\title{
Review \\ Clinical review: Beyond immediate survival from resuscitation - long-term outcome considerations after cardiac arrest
}

\author{
Dilshan Arawwawala and Stephen J Brett
}

Department of Anaesthesia and Intensive Care Medicine, Hammersmith Hospital, Du Cane Road, London W12 OHS, UK

Corresponding author: Stephen J Brett, stephen.brett@imperial.ac.uk

Published: 6 December 2007

This article is online at http://ccforum.com/content/11/6/235

(c) 2007 BioMed Central Ltd
Critical Care 2007, 11:235 (doi:10.1186/cc6139)

\begin{abstract}
A substantial body of literature concerning resuscitation from cardiac arrest now exists. However, not surprisingly, the greater part concerns the cardiac arrest event itself and optimising survival and outcome at relatively proximal time points. The aim of this review is to present the evidence base for interventions and therapeutic strategies that might be offered to patients surviving the immediate aftermath of a cardiac arrest, excluding components of resuscitation itself that may lead to benefits in long-term survival. In addition, this paper reviews the data on long-term impact, physical and neuropsychological, on patients and their families, revealing a burden that is often underestimated and underappreciated. As greater numbers of patients survive cardiac arrest, outcome measures more sophisticated than simple survival are required.
\end{abstract}

\section{Introduction}

Survival to a particular time after an 'index' cardiac arrest event, as recommended by the Utstein guidelines [1], is the most commonly reported outcome measure for resuscitation, with hospital discharge and 1-year survival often reported. Excessive mortality risk is greatest within the first year after arrest and, after 2 years, approaches that of an age- and gender-matched population [2]. A retrospective review of inhospital mortality identified neurological injury as the mode of early death in two thirds of out-of-hospital cardiac arrest (OOHCA) patients admitted to intensive care. Cardiovascular death and multi-organ failure death accounted for the remainder [3]. A number of studies have investigated survival rates at greater than 1 year and how survival following $\mathrm{OOHCA}$ has changed over time. Such studies suggest that longer-term survival figures are improving [4-7]. This may be due to changes in coronary artery disease patterns, resuscitation practice, and/or subsequent medical intervention.

With greater numbers of patients now surviving for longer periods, survival alone may be an inadequate assessment of resuscitation and post-resuscitation care. A more suitable tool may be assessment of quality of life (QOL) after hospital discharge. This requires an understanding of the psychosocial impact of cardiac arrest and its sequelae on the survivor and associated family members.

The aim of this review is to present the evidence base for interventions and therapeutic strategies that might be offered to patients surviving the immediate aftermath of an $\mathrm{OOHCA}$ (excluding components of resuscitation itself) which may lead to benefits in long-term survival. In addition, this paper reviews the data on long-term impact, both physical and neuropsychological, on patients and their families.

\section{Methodology}

Search terms recommended by the American Heart Association [8] and International Liaison Committee on Resuscitation (ILCOR) were used. These were used by working parties evaluating evidence for the ILCOR 2005 Consensus statement [9].

An electronic search of the literature by means of PubMed was conducted using MeSH (Medical Subject Heading) main search terms 'heart arrest' or 'cardiopulmonary resuscitation'. Additional terms recommended were 'antiarrhythmia agent', 'glucose', 'hypothermia' or 'induced hypothermia', 'defibril-

$\mathrm{ACE}=$ angiotensin-converting enzyme; $\mathrm{ADL}=$ activity of daily living; $\mathrm{AVID}=$ Antiarrhythmics Versus Implantable Defibrillators; $\mathrm{CABG}=$ coronary artery bypass grafting; CASH = Cardiac Arrest Study Hamburg; CIDS = Canadian Implantable Defibrillator Study; CPC = Cerebral Performance Category; DSM-IV = Diagnostic and Statistical Manual of Mental Disorders, Fourth Edition; ECG = electrocardiogram; I-ADL = instrumental activity of daily living; ICD = implantable cardiac defibrillator; IES = Impact of Event Scale; ILCOR = International Liaison Committee on Resuscitation; $\mathrm{LV}=$ left ventricular; $\mathrm{LVEF}=$ left ventricular ejection fraction; $\mathrm{MI}=$ myocardial infarction; $\mathrm{MMS}=$ mini-mental state; $\mathrm{MTH}=$ moderate therapeutic hypothermia; MUSTT = Multicenter Unsustained Tachycardia Trial; OOHCA = out-of-hospital cardiac arrest; OPC = Overall Performance Category; $\mathrm{P}-\mathrm{ADL}=$ personal activity of daily living; $\mathrm{PTSD}=$ post-traumatic stress disorder; $\mathrm{QOL}=$ quality of life; $\mathrm{ROSC}=$ return of spontaneous circulation; STEMI = ST segment elevation myocardial infarction; VF = ventricular fibrillation; $\mathrm{VT}=$ ventricular tachycardia. 
lators, implantable', 'seizures', 'thrombolytic therapy', 'angioplasty', 'coronary artery bypass grafting', and 'ventricular dysfunction'. The primary search identified a total of 4,431 papers. The following search limits were then applied: human, adult, and English language. Application of search limits reduced the initial search to 1,038 articles. Studies were then reviewed for relevance. We excluded papers if they were reviews, case reports, or referred to interventions prior to the return of a spontaneous circulation; 58 papers were identified. Additional papers were obtained from the reference list used by the ILCOR working parties for the 2005 Consensus statement and from a manual search of reference lists from reviewed papers. A total of 73 papers were identified as relevant for inclusion.

Using the search term 'quality of life' and the same primary search terms and limits, we identified 59 articles, of which 27 were relevant. A manual search of reference lists was also conducted, leading to the inclusion of another 13 articles.

Overall, the literature retrieved was somewhat diverse and was not suitable for meta-analysis. Specifically, papers did not consistently report the patient populations in terms of cause of cardiac arrest or whether they occurred in-hospital or out-of-hospital and there was substantial heterogeneity. Thus, the evidence was synthesised into a narrative review.

\section{Overview of long-term mortality}

Survival studies performed during the period 1970 to 1985 found a 4 -year survival of $40 \%$ to $61 \%$ [6,10-12]. Investigators (from several countries) examining long-term survival of patients discharged from the hospital following OOHCA have consistently shown an improvement. Pell and colleagues [5] showed that 5-year survival had improved in Scotland over a 10 -year period (1991 to 2001 ) from $64.2 \%$ to $76 \%$. This was due to a reduction in the risk of subsequent cardiac death. Part of this improvement was attributed to a higher percentage of patients less than 55 years of age and changes in clinical management after cardiac arrest. The subsequent use of beta-blockers, angiotensin-converting enzyme (ACE) inhibitors, antithrombotic agents, and revascularisation methods had increased over time. The authors also identified the increased use of implantable cardiac defibrillators (ICDs) and changes in smoking habits as reasons for the improvements observed [5]. Similar mortality results for OOHCA have been observed by Cobbe and colleagues [4], also in Scotland, for the period 1988 to 1994 , with a 4-year survival rate of $68 \%$. Rea and colleagues [13] found that long-term OOHCA survival in King County, WA, USA, had improved over a 26-year study period (1976 to 2001). Over each 5-year interval, cardiac mortality fell by $21 \%$ [13]. Again, the authors identified changes in clinical practice and lifestyle changes as being important. Data published from Olmstead County, MN, USA, from 1990 to 2001 of confirmed ventricular fibrillation (VF) cardiac arrests found a 5-year survival rate of $79 \%$ [7]. The higher figures obtained by these authors may reflect an enrolment bias as only patients with a confirmed initial rhythm of VF were included.

In contrast, Engdahl and colleagues [14] have shown no improvement in survival in a Swedish cohort between 1981 and 1998. Notable differences, when compared with data from Scotland, include the proportion of those surviving to hospital discharge with an initial rhythm of VF and the number of patients receiving bystander resuscitation [5]. Pell and colleagues [5] found that almost all (greater than 94\%) patients had an initial rhythm of VF or ventricular tachycardia (VT) compared with approximately $80 \%$ in the Swedish cohort. The number of patients receiving bystander resuscitation was consistently above $60 \%$ in the Scottish cohort compared with approximately $30 \%$ in the Swedish study. This lends support to current European Resuscitation Council recommendations on the need for early basic life support [15].

\section{Interventions}

Changes in survival represent the culmination of several medical advances that have occurred over the previous two decades. Improvements in primary and secondary prevention of coronary artery disease and changes in resuscitation have all contributed. Interventions shown to improve outcome following return of spontaneous circulation (ROSC) include optimisation of ventricular function immediately after the event, revascularisation, arrhythmia management, and therapeutic hypothermia (Table 1).

Revascularisation is integral to ventricular optimisation and arrhythmia management and will be discussed in conjunction with these interventions. The identification of the risk of ventricular arrhythmias after cardiac arrest by electrophysiological testing can predict long-term outcome. Thus, Wilber and colleagues [16] examined 166 survivors of OOHCA not associated with acute myocardial infarction (MI) and identified, over a mean follow-up of 21 months, a 33\% (12/36) cardiac arrest recurrence rate in patients with inducible, but not suppressed, arrhythmias. This was compared with $12 \%$ $(11 / 91)$ in whom inducible arrhythmias had been suppressed by surgery or antiarrhythmic agents [16].

\section{Revascularisation}

Cardiac arrest survivors with significant coronary atherosclerotic disease have a $20 \%$ chance of VF recurrence at 1 year [17-19]. Of those admitted to hospital immediately after cardiac arrest, almost half have coronary artery occlusion. Furukawa and colleagues [20] showed, in postarrest patients with chronic coronary artery disease, ventricular arrhythmias unresponsive to therapy to be predictive of higher 2-year mortality. Patients surviving $\mathrm{OOHCA}$ often have a reversible ischaemic cause for their cardiac arrest. Ventricular arrhythmias as a cause of cardiac arrest often are associated with myocardial ischaemia. Bunch and colleagues [21] identified that $78 \%(66 / 79)$ of VF 


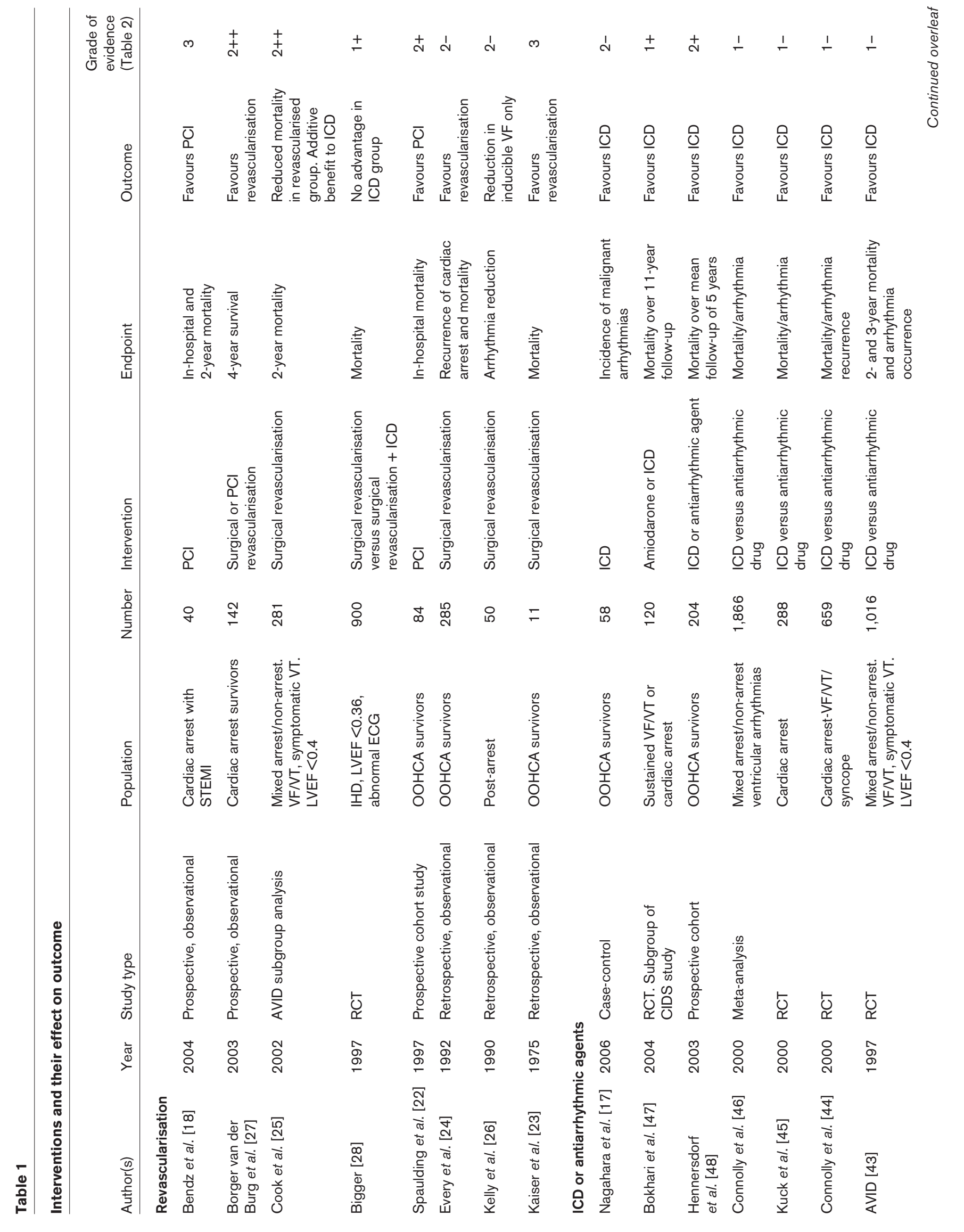




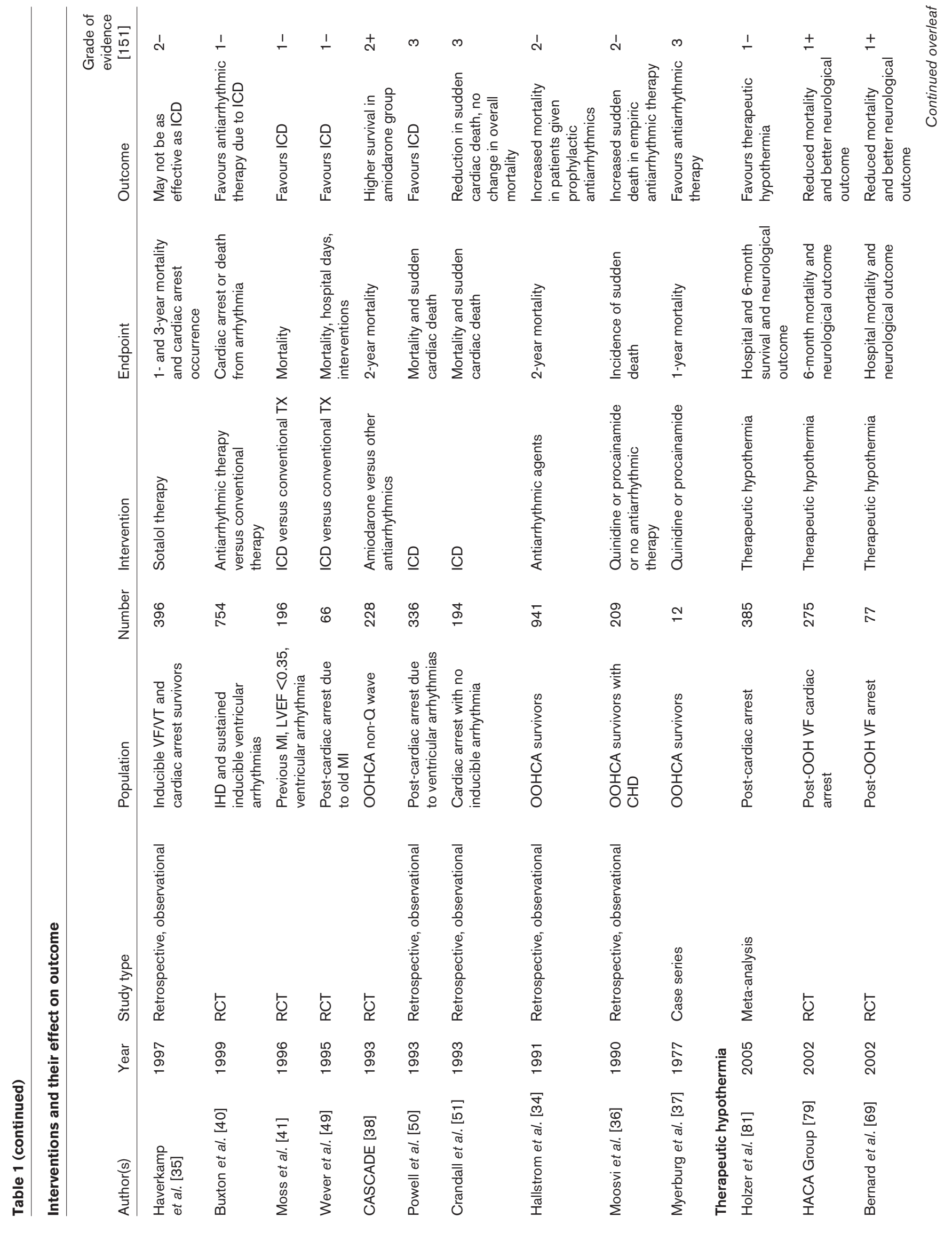


OOHCA patients surviving to hospital discharge had ischaemic heart disease, with $47 \%$ of these presenting with an acute Ml. Similar findings have been reported from Göteborg, Sweden, and Glasgow, Scotland [10,14].

Although there is a large body of evidence validating thrombolysis in patients with ST segment elevation myocardial infarction (STEMI), our search revealed no literature specific to a post-cardiac arrest subgroup in whom a spontaneous circulation has returned. Though relatively contraindicated in patients with prolonged cardiopulmonary resuscitation, thrombolysis would not be unreasonable to use in those patients with electrocardiogram (ECG) evidence of recent coronary artery occlusion. Clinical and ECG findings, however, may not predict arterial occlusion, and immediate angioplasty can improve survival to hospital discharge [22]. Angiography can identify the presence of thrombusassociated coronary artery occlusion that may be the cause of cardiac arrest.

Revascularisation may improve survival through myocardial salvage. Bendz and colleagues [18] showed that $\mathrm{OOHCA}$ patients with ECG-confirmed STEMI receiving primary angioplasty had a survival rate comparable to a control non-cardiac arrest STEMI group 2 years after hospital discharge. However, the study included only patients with an arrest-toresuscitation time of less than 10 minutes and thus may have enrolled only those with a higher probability of survival. Unfortunately, no data on the incidence of arrhythmia postrevascularisation were given [18].

Retrospective case series have identified coronary artery bypass grafting (CABG) as a tool in reducing the incidence of recurrent arrest and prolonging survival after STEMI OOHCA [23,24]. Data extracted from the Antiarrhythmics Versus Implantable Defibrillators (AVID) study showed, in 281 patients (presenting with ventricular arrhythmias) who received CABG, an improvement in 5-year survival independent of ICD implantation [25]. A retrospective observational study of 50 post-cardiac arrest patients identified a reduction in inducible arrhythmias following CABG; VF was no longer inducible in all 11 patients who had inducible VF pre-operatively. In contrast, $80 \%$ of patients with inducible VT pre-operatively still had the arrhythmia following surgery [26]. Ventricular arrhythmia cardiac arrest survivors with coronary artery disease and non-inducible arrhythmias had a $100 \%$ survival rate $(n=18)$ over a 4 -year follow-up (range, 1 to 48 months) compared with $87 \%$ (18/80) in patients not revascularised with inducible arrhythmias [27]. The CABG Patch trial, a prospective study of 900 patients with a left ventricular ejection fraction (LVEF) of less than 0.36 and ECG abnormalities scheduled for elective CABG who were randomly assigned to ICD or standard medical therapy, found that ICD use conferred no additional survival benefit to patients at high risk of arrhythmia formation [28]. In the control limb, the arrhythmia rate was low, implying that 
Table 2

\begin{tabular}{|c|c|}
\hline Level of evidence & Evidence required \\
\hline $1++$ & High-quality meta-analyses, systematic reviews of randomised controlled trials (RCTs), or RCTs with a very low risk of bias \\
\hline $1+$ & Well-conducted meta-analyses, systematic reviews of RCTs, or RCTs with a low risk of bias \\
\hline $1-$ & Meta-analyses, systematic reviews of RCTs, or RCTs with a high risk of bias \\
\hline $2++$ & $\begin{array}{l}\text { High-quality systematic reviews of case-control or cohort studies } \\
\text { High-quality case-control or cohort studies with a very low risk of confounding, bias, or chance and a high probability that } \\
\text { the relationship is causal }\end{array}$ \\
\hline $2+$ & $\begin{array}{l}\text { Well-conducted case-control or cohort studies with a low risk of confounding, bias, or chance and a moderate probability } \\
\text { that the relationship is causal }\end{array}$ \\
\hline $2-$ & $\begin{array}{l}\text { Case-control or cohort studies with a high risk of confounding, bias, or chance and a significant risk that the relationship is } \\
\text { not causal }\end{array}$ \\
\hline 3 & Non-analytic studies (for example, case reports and case series) \\
\hline 4 & Expert opinion \\
\hline
\end{tabular}

revascularisation reduces the incidence of arrhythmia formation and subsequent death. Revascularisation reduces the incidence of cardiac ischaemia that commonly precedes potentially fatal ventricular arrhythmias [29,30]. However, some patients following CABG may still have malignant arrhythmias. A case series of 23 cardiac arrest survivors discovered that $43 \%$ of patients received at least one ICD shock (range, 1 to 22 shocks) over a mean follow-up of 34 months. All patients had received CABG for ischaemia and were non-inducible with programmed stimulation [31].

Not all patients with potentially fatal arrhythmias have operable coronary artery disease. Therefore, revascularisation as a tool for arrhythmia management can be useful only in a specific cohort of patients. Though not specifically described in the post-cardiac arrest population, beta-blockers, aspirin, and statins have all been shown to prolong survival in patients with ischaemic heart disease. Thus, current guidelines produced by a task force representing the American Heart Association and American College of Cardiology state that patients with peri-Ml ventricular arrhythmias in whom ischaemia is fully reversed do not require an ICD and that those with ischaemia not fully reversible should receive an ICD [32].

Thus, revascularisation appears to improve survival through a reduction in malignant arrhythmias and, potentially, myocardial salvage. There is currently no evidence supporting the use of thrombolysis in patients post-arrest without electrographic evidence of acute MI. The literature suggests that there should be a greater use of early angiography and electrophysiological testing to identify the presence of reversible ischaemia and the need for revascularisation or the use of ICD or antiarrhythmic agents. Although there is more evidence supporting the use of CABG compared with percutaneous angioplasty, this may be purely historical and requires further assessment.

\section{Pharmacological and electrical rhythm stabilisation}

Pharmacological and electrical methods often are employed to prevent the recurrence of arrhythmias, with amiodarone commonly used for arrhythmia prevention [33]. Retrospective studies of antiarrhythmic drug use after cardiac arrest have produced conflicting results [34-37]. The CASCADE (Cardiac Arrest in Seattle: Conventional Versus Amiodarone Drug Evaluation) study, a randomised multi-centre study of 228 patients post-VF confirmed cardiac arrest with electrophysiological evidence of an increased risk of further episodes, showed amiodarone to be superior to other antiarrhythmic agents at preventing VF arrests, sudden cardiac arrest, and ICD triggering episodes at 2, 5, and 6 years after the event [38]. However, the increasing use of ICDs may have a role in reducing long-term mortality, especially the high mortality rate seen in the first year after hospital discharge. Several observational studies have seen an increase in long-term survival and an increase in ICD use over the same time frames $[10,13,14]$. Pell and colleagues [5] estimated a 5-year mortality reduction if all patients fitting the criteria for ICDs had received them.

The role of ICDs for ventricular arrhythmia management has been proven in randomised controlled trials. The Multicenter Unsustained Tachycardia Trial (MUSTT) prospectively randomly assigned 754 patients (with coronary artery disease, an LVEF of less than 40\%, and spontaneous unsustained tachycardia or sustained tachycardia on electrophysiological manipulation) to either antiarrhythmic therapy (pharmacological or electrical) or conventional medical therapy (betablockers/ACE/diuretics/aspirin). The mean follow-up was 39 months. A $7 \%$ absolute risk reduction of death from arrhyth- 
mia or cardiac arrest was found in those randomly assigned to antiarrhythmic therapy. This was solely due to the use of ICDs and not pharmacological therapy [39]. Patients with ICDs not only had fewer cardiac arrests and arrhythmias, but also had improved survival every year for 5 years after enrolment compared with other study patients. Of those assigned to pharmacological agents, only $10 \%$ received amiodarone compared with more than $40 \%$ receiving class I antiarrhythmic agents. Whether this may have biased the result is uncertain [40]. The MADIT I (Multicenter Automatic Defibrillator Implantation I) study, a prospective randomised trial of 196 patients with inclusion criteria similar to those of the MUSTT study, identified a statistically significant positive outcome for those assigned to ICDs compared with pharmacological agents (54\% 2-year reduction in all-cause mortality). The main antiarrhythmic agent in this study was amiodarone $[41,42]$.

Specific to post-cardiac arrest patients, a meta-analysis of three randomised controlled trials (AVID, Canadian Implantable Defibrillator Study [CIDS], and Cardiac Arrest Study Hamburg [CASH]) investigated the role of ICDs versus amiodarone in ventricular arrhythmia reduction and mortality [43-47]. The meta-analysis concluded that there was a $27 \%$ reduction in the relative risk of dying (absolute reduction of $3.5 \%$ per year) and this was due almost entirely to a $50 \%$ reduction in arrhythmic death. The three studies enrolled patients with ventricular arrhythmias, the majority after cardiac arrest. The combined mean follow-up period was $2.3( \pm 1.89$ standard deviation) years. Patients with an LVEF of less than $35 \%$ benefited significantly more from an ICD than those with a greater ejection fraction. The prospective multi-centre CASH study of 288 patients post-cardiac arrest (secondary to sustained ventricular arrhythmias) randomly assigned patients to ICD or amiodarone or metoprolol. The minimum follow-up period was 2 years, with a mean of $57 \pm 34$ months. Overall mortality rates from all causes were $36.4 \%$ in the ICD arm and $44.4 \%$ in the antiarrhythmic arm (23\% reduction). Although this was not statistically significant, there were fewer sudden deaths in the ICD group; $73 \%$ had evidence of coronary artery disease, raising the question of whether revascularisation would have altered the results.

The AVID study was the only one to show a statistically significant difference. The AVID population consisted of patients with documented VF or symptomatic VT, whereas the CASH and CIDS studies were confined to cardiac arrest survivors. More than a third of the AVID study patients were not post-cardiac arrest. There were other significant differences in the inclusion criteria between the three studies. The AVID study, with more than 500 patients in each limb, identified a superior all-cause and arrhythmic death reduction (all-cause deaths $16.5 \%$ versus $10 \%$, arrhythmic deaths $7.4 \%$ versus $3 \%$, and $27 \%$ reduction in all-cause mortality at 2 years). The follow-up period was only 1.5 years as a statistically significant benefit of ICDs led to the early termination of the study. The longest follow-up period described has been 11 years. Patients reported were a subgroup of those enrolled from one centre into the CIDS study. Total mortality was $5.5 \%$ per year in the amiodarone group compared with $2.8 \%$ in the ICD group. Patients receiving amiodarone had not only a statistically higher mortality but also a greater recurrence of arrhythmias and drug side effects [47]. Similar results have been reported by Hennersdorf and colleagues [48] in Düsseldorf, Germany. This echoes a previous smaller study with a mean follow-up of 27 months [49].

A two-centre retrospective cohort study (Massachusetts/Los Angeles) of $331 \mathrm{OOHCA}$ patients discharged from the hospital identified that $71 \%$ had coronary artery disease and reduced ventricular function, $97.6 \%$ had a ventricular arrhythmia as the cause of their arrest, and median follow-up was 35 months (range, 1 to 151 months). More deaths (34.3\% versus $19.3 \%$ ) and sudden cardiac deaths (14.4\% versus $3.3 \%$ ) occurred in patients without an ICD. Multivariate analysis identified predictors of cardiac mortality as an LVEF of less than 0.4 , absence of ICD, and the presence of inducible VT before hospital discharge. Patients with ICDs had a lower mean follow-up period and less coronary disease, which may have influenced the overall outcome [50]. A retrospective study of 194 survivors of OOHCA with no significant inducible arrhythmias on electrophysiological testing identified that patients receiving an ICD had a lower incidence of sudden cardiac death. However, there was no change in overall mortality compared with those without an ICD. Patients with an ICD were younger and had significantly less coronary artery disease, which may have biased the results [51]. A prospective study of 204 patients post-cardiac arrest identified a significant reduction in mortality in patients (with inducible tachycardia) receiving ICD compared with those receiving antiarrhythmic agents. The mean follow-up period was 57 months [48]. ICDs in conjunction with additional antiarrhythmic agents have been compared with ICD therapy alone. A prospective multi-centre study randomly assigned patients with ICDs to amiodarone and beta-blocker, sotalol, or a beta-blocker (metoprolol, carvedilol, or bisoprolol) for 1 year. Patients had to have sustained VT, VF inducible VT or VF by programmed ventricular stimulation, or cardiac arrest (and an LVEF of less than 40\%) as the reason for ICD insertion. The main outcome measure was ICD shock for any reason. Shocks occurred in $38.5 \%$ assigned to beta-blocker alone, $24.3 \%$ in the sotolol group, and $10.3 \%$ in the amiodarone and beta-blocker group. Given that ICD shocks are painful, this may help to improve patient acceptance of the devices [52].

Much of the evidence for arrhythmia management and its influence on long-term survival originated from patients with proven arrhythmias who were not specifically post-cardiac arrest. Although there is less evidence available for postcardiac arrest patients, the studies available are prospective, 
randomised with large populations, and conclude that ICDs are superior to pharmacological agents alone at preventing further arrhythmias and prolonging survival. Although ICDs prevent sudden death, they add a considerable cost impact to patient care and produce painful shocks. Patient selection and, possibly, combined pharmacological therapy are important factors when looking to provide cost-effectiveness. Revascularisation remains an option for a specific subgroup of patients with reversible ischaemia.

\section{Cardiac dysfunction post-arrest}

Negovsky [53] described a multi-organ dysfunction syndrome that affects cardiovascular, neurological, pulmonary, and metabolic systems and that occurs after ROSC. Postresuscitation myocardial dysfunction is now recognised as a separate entity from myocardial stunning secondary to coronary artery occlusion and may lead to a worse prognosis [54]. Patients often require inotropic support following a cardiac arrest for depressed ventricular function; this often reverses within 24 to 48 hours [55-57]. In animal studies, global myocardial stunning has been linked to ischaemia duration, the number and type of defibrillation shocks, and the total dose of epinephrine used during resuscitation [58-63]. A prospective study of transthoracic echocardiography performed 6 hours after ROSC following OOHCA found, on multiple regression analysis, prolonged cardiopulmonary resuscitation, defibrillation, and high-dose epinephrine (greater than $5 \mathrm{mg}$ ) to be associated with poor left ventricular (LV) systolic function. Patients with an LVEF of less than $40 \%$ had a higher mortality over the course of 60 days after the event and significantly worse neurological outcomes (as assessed by Cerebral Performance Category [CPC] scores, see Table 3). Impaired LV diastolic function, assessed by isovolumetric relaxation times, was associated with nonVF/VT cardiac arrests and was an independent predictor of a poor outcome [64]. Attempts to correct the dysfunction mechanically and pharmacologically may lead to improved long-term outcomes. As yet, however, there is little robust evidence on which to base specific recommendations [65-68].

\section{Therapeutic hypothermia after cardiac arrest}

Neurological injury accounts for a high proportion of early mortality in hospital and within the first year after discharge. Mechanisms described include reperfusion injury, production of free radicals and excitotoxic agents, the activation of degenerative enzymes, and reduced cerebral blood flow after arrest [69-73]. Animal studies have shown that mild therapeutic hypothermia $\left(34^{\circ} \mathrm{C}\right.$ to $\left.36^{\circ} \mathrm{C}\right)$ can limit the degree of brain injury by minimising the above processes $[74,75]$. Some therapeutic benefit is lost if there is a delay (greater than 15 minutes after ROSC) in instituting hypothermia [76].

Human studies have shown that moderate therapeutic hypothermia (MTH) reduces hospital mortality and improves neurological outcome [69,77-80]. Bernard and colleagues [69] randomly assigned 77 post-OOH VF patients to normothermic or $\mathrm{MTH}\left(33^{\circ} \mathrm{C}\right)$ therapy. Survival to hospital discharge was improved in the MTH group (49\% versus 33\%) with higher Overall Performance Category (OPC) scores [69] (Table 3). The Hypothermia After Cardiac Arrest Study Group randomly assigned 275 witnessed VF/VT arrest patients to either maintenance of normothermia or MTH $\left(32^{\circ} \mathrm{C}\right.$ to $\left.34^{\circ} \mathrm{C}\right)$ for 24 hours after arrest. Survival at 6 months was higher in the hypothermic group (59\%) compared with the normothermic group (45\%), with less neurological injury as assessed by CPC scores. Fifty-five percent of all patients in the treatment limb demonstrated a favourable neurological outcome (CPC 1 to 2) at 6 months compared with $39 \%$ in the control limb [79]. A subsequent meta-analysis of therapeutic hypothermia in post-VF arrest patients found that the number needed to treat to prevent one unfavourable neurological outcome was 6 (confidence interval, 4 to 13). Although the results are consistent, key differences between the studies used in the meta-analysis include: presenting rhythm, method of cooling, time taken to reach target temperature and duration of hypothermia [81]. To our knowledge, there have been no follow-up studies of long-term (greater than 1 year) neurological outcome of patients treated with post-arrest hypothermia.

Despite the strict inclusion criteria, which may have led to enrolment bias, similar findings have been described in other studies $[69,71,78,82]$. Hypothermia has now been recommended by ILCOR and adopted into resuscitation guidelines as part of the 'chain of survival'. Although the evidence to date has been primarily from VF OOHCA, ILCOR recommend that it be considered a treatment option for non-VF OOHCA [83]. Adopting therapeutic hypothermia as routine practice, however, has not occurred in some regions. Reasons given include technical difficulty and a perceived lack of evidence [84-87]. Although the evidence to date has been directed at improvements at 6 months to 1 year, it is reasonable to presume a long-term neurological benefit, but further follow-up studies are required to validate this statement.

\section{Glycaemic control}

Glycaemic control (80 to $110 \mathrm{mg} / \mathrm{dL}$ ) in a critically ill population may provide short- and long-term survival benefits and is recommended in the management of patients with sepsis. Though an area of controversy, reducing the incidence of infection appears to account for much of the observed benefit [88,89]. Van den Berghe and colleagues [90] identified mortality benefit in critically ill medical patients managed with strict glycaemic control for a minimum of 3 days. The majority of OOHCA patients would fulfil both criteria and therefore may benefit [90]. Studies examining patients with brain 'injuries', however, are not conclusive. High mean glucose levels in patients with subarachnoid haemorrhage are associated with a poor neurological outcome and increased mortality. The Glucose Insulin in Stroke Trial, which used glucose/insulin/potassium infusions for 24 hours after admission to maintain serum glucose 
Table 3

\section{Scoring system}

Scoring system

EQ-5D

RAND 36

$15 \mathrm{D}$

Cerebral Performance Category (CPC)

Overall Performance Category (OPC)

Activities of Daily Living (ADLs)

Functional Independence

Measure $\left(\mathrm{FIM}^{\text {Tw}}\right)$

Symptom Checklist 90 Revised score

Impact of Event Scale

Post-traumatic Diagnostic Scale

MMS

Hospital Anxiety and Depression Scale

\section{Description}

Five questions on mobility, self-care, everyday activities, pain, and state of mind, each with three possible answers. Total score: 0 to 100. The higher the score, the better the quality of life.

36 questions/statements on physical and emotional health with two to six choices for each question.

15 dimensions with five levels that describe state of health. Patient chooses which best describes their state.

CPC 1: Conscious. Alert and able to work and lead a normal life. May have minor psychological or neurological deficits. CPC 2: Moderate cerebral disability. Conscious. Sufficient cerebral function for part-time work in sheltered environment or independent activities of daily life. May have hemiplegia, seizures, ataxia, dysarthria, or permanent memory or mental changes.

CPC 3: Severe cerebral disability. Conscious. Dependent on others for daily support because of impaired brain function. CPC 4: Coma, vegetative state.

CPC 5: Death. Certified brain dead or dead by traditional criteria.

OPC 1: Healthy, alert, capable of normal life. Good cerebral performance (CPC 1) plus no or only mild functional disability from non-cerebral organ system abnormalities.

OPC 2: Moderate overall disability. Conscious. Moderate cerebral disability alone (CPC 2) or moderate disability from non-cerebral system dysfunction alone or both. Performs independent activities of daily life. May be able to work part-time in sheltered environment but disabled for competitive work.

OPC 3: Severe overall disability. Conscious. Severe cerebral disability alone or severe disability from non-cerebral organ system dysfunction alone or both. Dependent on others for daily support.

OPC 4: Same as CPC 4.

OPC 5: Same as CPC 5.

Personal ADLs assess bathing, dressing, toilet visit, mobility, continence, and eating. Instrumental ADLs assess cleaning, shopping, cooking, and transportation.

An 18-point scale scoring from 1 to 7 , with 7 being complete independence. Outcomes measured include self-care, sphincter control, transfers, locomotion, communication, and social cognition.

A 90-item self-report test designed to reflect psychological symptom patterns within the last 7 days.

A 15-point self-report questionnaire designed to assess current subjective stress for any specific life event.

A 49-point self-report-style questionnaire aimed at assisting with the diagnosis of post-traumatic stress disorder.

A 30 point scale. Results in the range $0-23$ indicate disturbance of cognition. Fields assessed are: Orientation, registration, attention and calculation, recall, language

Seven questions for anxiety and seven questions for depression with a choice of four answers for each. Scores from 0 to 3 for each question, depending on answer given. The higher the total score, the more likely it is that affective symptoms are present. between 4 and $7 \mathrm{mmol} / \mathrm{L}$, identified no mortality benefit. This study was underpowered due to slow recruitment [91-93]. The role of glucose control after OOHCA has been difficult to establish due to confounding factors (for example, time to ROSC) [94,95]. A prospective study of 145 patients admitted following ROSC from a witnessed VF arrest examined the association of glucose levels in neurological outcome. Patients receiving insulin or with a history of diabetes were excluded from the study. A significantly better neurological outcome (as assessed by CPC scores) at 6 months was identified in patients with lower median 24-hour glucose levels (146 $\pm 39 \mathrm{mg} / \mathrm{dL}$ interquartile range) compared with those with higher levels $(184 \pm 88 \mathrm{mg} / \mathrm{dL})$ even after controlling for duration of arrest and lactate levels [96]. A retrospective observational study of $461 \mathrm{OOHCA}$ patients identified, by multivariate analysis, that a glucose level of greater than $10.6 \mathrm{mmol} / \mathrm{L}$ within the first 24 hours after admission was associated with significantly higher hospital mortality [97]. A retrospective study of 98 patients identified mean blood glucose as being an independent predictor of survival at 6 months [98]. Whether glycaemic control confers longer survival and neurological benefits is unclear. High glucose levels may be a surrogate marker for the severity of brain injury incurred, reflecting the release of stress hormones (for example, cortisol, glucagon, and epinephrine). A study randomly assigning survivors of $\mathrm{OOHCA}$ to tight glycaemic control or no glucose control would, given the current levels of evidence for glycaemic control in critical care studies, be unethical. A sensible approach would be to prevent hyperglycaemia following $\mathrm{OOHCA}$. 


\section{Anticonvulsant prophylaxis, thrombolysis, and neurological outcome}

Seizure activity after cardiac arrest is common, with observational studies identifying an incidence of up to $36 \%$ $[99,100]$. It is associated with a poor neurological outcome. However, the presence of seizure activity is likely to be the effect of significant cerebral injury. Small animal studies have described a reduction in the neuronal damage after cardiac arrest with lamotrogine and fosphenytoin [101,102]. There are, to date, no human studies examining whether anticonvulsant therapy affects patient outcome in this context.

Small animal studies have demonstrated that peri-arrest thrombolysis can improve cerebral microcirculation flow and electroencephalogram readings immediately after ROSC $[103,104]$. To date, there are no human studies or case reports of thrombolysis being used after ROSC to improve neurological outcome. Given the level of available evidence, no recommendation can be made for the routine use of thrombolysis or prophylactic anticonvulsant drugs.

Nishizawa and Kudoh [105] studied eight patients after $\mathrm{OOHCA}$ and discovered jugular bulb venous blood oxygen saturation altered in direct proportion to changes in mean arterial pressure. Impairment of cerebral autoregulation may be due to cerebral ischaemia accompanying cardiac arrest [105]. Similar results were obtained by Sundgreen and colleagues [106], identifying either a loss or right shift in cerebral autoregulation. Maintaining an appropriate mean arterial pressure may lead to less secondary brain injury. Although these are areas of considerable interest which may provide potential therapeutic avenues, recommendations cannot be made without further research.

\section{Neurocognitive and functional outcome: effects on survivors and families \\ Gross neurological outcome}

When assessing how successful a resuscitation attempt has been, the initial Utstein recommendations focussed on survival at hospital discharge, with function assessed by CPC and OPC at discharge [107-109]. As up to $90 \%$ of hospital mortality following OOHCA is attributed to brain injury, this seems an appropriate outcome measure [110].

In Olmstead County, of patients who experienced a VF OOHCA, 145 (72\%) patients were admitted alive, 79 (54\%) survived to hospital discharge, 75 patients discharged had an OPC score of 1 , and 5 patients discharged had a score of 2 (Table 3 ). Five patients were transferred to a nursing home with an OPC score of 3 to 4 [21]. Engdahl and colleagues [14] found that fewer patients were being discharged home with a CPC score of 1 or 2 over a 20-year period (1981 to $1991,78 \%$; 1991 to $1998,63 \%$ ) and more patients were being discharged to nursing homes and rehabilitation clinics. Such differences may reflect the study populations and community services available. A cause for the increase in patients requiring long-term care may be advances in periarrest management, with more patients surviving with what, historically, would have been unsurvivable brain injuries. Importantly, gross neurological outcome may improve with time. Among patients who had a CPC score of 2 at discharge, 77\% improved to a CPC score of 1 one year later. Among patients with a CPC score of 3 at discharge, 25\% improved to a CPC score of 2 and $4 \%$ to a CPC score of 1 one year later [111].

Mortality data give no indication of whether an individual returns to any degree of normal neurological function, and CPC/OPC, as somewhat gross measures, tend not to correlate with $\mathrm{QOL}$ as judged by questionnaires and structured interviews. Hsu and colleagues [112] studied 35 patients at an average of 7 months after arrest and found that CPC correlated poorly with QOL. A CPC score of 1 on discharge had a sensitivity of $78 \%$, a specificity of $43 \%$, a positive predictive value of $64 \%$, and a negative predictive value of $60 \%$ for a QOL that was the same as or better than before the cardiac arrest [112]. Recent recommended guidelines (from participants of the Utstein Consensus Symposium) for research into in-hospital post-resuscitation care suggest the use of QOL markers as a measure of the effectiveness of care as well as outcome [113]. Three QOL scales are now recommended. These are the EQ-5D, the RAND 36, and the 15D [114-116] (Table 3).

\section{Functional outcome and quality of life}

Functional assessment is often made using activities of daily living (ADLs). Two different scales have been described: personal ADL (P-ADL) and instrumental ADL (I-ADL) (Table 3) $[117,118]$. Survivors of cardiac arrest frequently remain dependent on others for most activities. A prospective cohort study of patients after OOHCA examined ADLs 1 year after cardiac arrest, reporting that $5 / 26$ patients remained dependent [119]. A small retrospective study with an average follow-up of 25 months found that P-ADL was a problem for $3 / 20$ patients and that $7 / 20$ patients were dependent for I-ADLs [120]. Grosvasser and colleagues [121], using a similar scoring system, found that $17 / 31$ patients were dependent when followed up at least 3 years after the event. Lundgren-Nilsson and colleagues [110] assessed ADL using the Functional Independence Measure $\left(\mathrm{FIM}^{\mathrm{TM}}\right)$ and the Instrumental Activity Measure (Table 3). They found that $61 \%$ were dependent for motor performance and $65 \%$ for social cognitive areas when assessed within 2 weeks of their cardiac arrest. The level of dependence fell at 45 days after the event to $43 \%$ (motor) and 56\% (social cognitive) with no significant improvement between 45 days and 1 year [110].

Another marker of recovery often used is a return to prearrest social activities, including employment. The study of Pußwald and colleagues [122] of 12 survivors at a median period of 25 months after hospital discharge found that none 
had returned to employment. Grosvasser and colleagues [121] found that only 1 of 31 survivors was back to work 3 years after the cardiac arrest. A retrospective study from San Francisco, CA, USA, found that, of 61 survivors, 36 had been in employment prior to their cardiac arrest. At 6 months, this figure had fallen to 26 and to 16 at 1 year. The largest fall was in those in full-time employment ( $46 \%$ to $18 \%$ at 1 year). The mean age of this group was 48 years. The main reasons given for not returning to work were the occurrence of symptoms with exercise, impairment of intellectual function, and approaching retirement age [123]. These findings are similar to those of earlier studies [124,125].

Granja and colleagues [126] used the EQ-5D to assess health-related QOL in 19 survivors at 6 months. Eight were working and six of these had returned to their previous level of activity. Eleven were already retired, with seven returning to previous levels of activity. Those assessed had a 'good' QOL. No significant differences were found when compared with a general critical care control group [126]. A retrospective observational study of $\mathrm{OOHCA}$ patients in Rotterdam, The Netherlands, found that 109 (83\%) hospital survivors returned questionnaires and had a mean EQ-5D visual analogue scale score of 85/100, representing a good QOL [127]. Thus, the above studies show that, although CPC and OPC scores are often used, they may be insensitive and do not truly reflect functional status.

\section{Memory and cognitive dysfunction}

Cognitive impairment is common after cardiac arrest. A study of 25 patients identified that $72 \%$ of patients had mild to severe impairment in at least one cognitive area at hospital discharge, with memory being the most common deficit; time to post-arrest wakening was most predictive of longer-term cognitive outcome [128]. A retrospective study of 12 patients with anoxic injury of cardiac origin assessed a median of 25 months after injury found that all had evidence of impairment in areas such as memory, orientation, alertness, and awareness. Three syndromes were identified: severe physical and intellectual impairment, dementia, and amnesic syndrome. Extrapolating this evidence is difficult as all patients had confirmed brain damage and had undergone prolonged rehabilitation, thus are unlikely to be representative of all survivors [129]. A prospective randomised study of 68 OOHCA survivors by Roine and colleagues [130] showed that $48 \%$ still had evidence of cognitive impairment at 1 year, the incidence at 3 months being 60\% measured with the mini-mental state (MMS) scoring system. Using the MMS scoring system, Sunnerhagen and colleagues [120] found that persisting cognitive impairment was still present at 2 years after the event, with cognitive impairment occurring in $35 \%$ of survivors studied. The better result may reflect differences in cardiac arrest populations, population sizes, or length of time since the event. One notable difference between the two studies was the time from arrest to arrival of emergency medical services. Arrival times were shorter in the study of Sunnerhagen and colleagues compared with the population of Roine and colleagues, suggesting that the interval from arrest to commencement of cardiopulmonary resuscitation (and so cerebral perfusion) is important for longterm neurological outcome. Others have found memory and concentration to be still impaired 3 to 4 years after the event compared with control populations [129,131-134]. The above studies all suggest that cognitive impairment, especially concentration, is common after cardiac arrest. Moreover, the studies exclude patients with severe neurological impairment, thus masking the true proportion of impaired survivors. Maximal recovery appears to occur early, with long-term cognitive impairment a real possibility.

\section{Affective disorders}

In the early phase after a cardiac arrest, a high prevalence of anxiety and panic symptoms has been described [135,136]. Anxiety, depression, anger, stress, and confusion are highest at hospital discharge. A prospective randomised study examining the effect of nimodipine on neurocognitive sequelae after cardiac arrest found that $69 \%$ of all patients surviving to 1 year had depressive symptoms when tested with the Symptom Checklist 90 Revised score (Table 3). Nimodipine had no effect on the cognitive functions tested [130]. O'Reilly and colleagues [137] performed a retrospective case-control study of 27 patients from Scotland who were enrolled within 18 months of their resuscitation and assessed with the Hospital Anxiety and Depression Scale (Table 3). Clinical anxiety and depression were more common in the post-cardiac arrest group compared with the Ml control group (30\% versus $7 \%$ and $15 \%$ versus $0 \%$, respectively). Statistical significance was reached only for depression [137]. Reasons for these discrepancies probably lie in the different assessment tools used and the variable and unmeasured level of support and care provided. Whether these symptoms persist in the long term is unclear. Some investigators have reported that affective symptoms tend to decline over the following year, with the greatest reduction reported at 6 months after discharge [123,138,139].

\section{Post-traumatic stress disorder symptoms}

One of the core criteria for developing post-traumatic stress disorder (PTSD) is the experiencing of an event that was an actual or perceived threat to life. Serious illness is now included as such an event in the Diagnostic and Statistical Manual of Mental Disorders, Fourth Edition (DSM-IV) [140]. In their case-control study, O'Reilly and colleagues [137] found that five (19\%) cardiac arrest survivors and two (7\%) MI survivors fulfilled DSM-IV criteria for PTSD when assessed by structured clinical interview, the Impact of Event Scale (IES), and a self-reporting questionnaire (Post-traumatic Diagnostic Scale) (Table 3). There was, however, relatively poor agreement between the interviews and self-report diagnoses [137]. A similar-sized study from Munich, Germany, using IES, examined patients 2 to 5 years after the event and found that $8 / 21$ patients had PTSD symptoms 
associated with significantly higher scores for depression and anxiety. Patients with PTSD symptoms reported a lack of confidence in the future and low estimates of their mental and somatic condition, tending to report more physical symptoms. Further analysis identified that sedation at illness onset reduced the risk of developing PTSD by fivefold [131]. The mean duration of unconsciousness in those sedated was 618 minutes compared with 92 minutes in those not sedated. The authors speculate that prolonged sedation may inhibit imprinting of painful and adverse stimuli; also, awakening in a more controlled environment may generate more positive emotions.

Neurocognitive and affective disorders in critical illness Depression, anxiety, and avoidance symptoms are common among patients discharged from general intensive care units [141]. In medical intensive care patients, 33\% to $78 \%$ of survivors had neurocognitive impairment at 6 months to 1 year. This can still be present 6 years later [142-145]. Suggested mechanisms include hypoxia, hyperglycaemia, and ischaemia. Sedative and analgesic drugs and sepsis may also contribute [146]. Many OOHCA patients spend a significant period of time in a critical care environment. Thus, cognitive and psychological disorders may be, in part, a generic consequence of critical illness rather than the sequelae of the cardiac arrest itself.

\section{Information from qualitative studies}

Several qualitative studies have investigated the broader aspects of patient survival from the perspective of the individual and family. Dougherty and colleagues [147] examined this in survivors of $\mathrm{OOH}$ VF arrest who then received an ICD. Thirteen survivors and family members were followed up over 1 year after hospital discharge. Using structured questionnaires and interviews, they identified 'domains of concern' and the strategies implemented to cope with these issues. Common areas of concern for partners were the physical and emotional care of the survivor, finding time for their own well-being, relationship changes, understanding ICDs and dealing with shocks, money worries, and communicating with health care providers [138,147]. A study of eight survivors of cardiac arrest with ICDs by Tagney and colleagues [148] from Bristol, UK, reported similar observations. They also found that overprotectiveness of families led to reduced levels of activity and increasing dependence with subsequent loss of confidence. Survivors had concerns over altered body image due to the implanted defibrillator and often concealed symptoms, emotions, and concerns about their ICD from their family. Fear of ICD shocks and possible death may limit physical recovery, including sexual activities [148]. Dougherty and colleagues [147] and Tagney and colleagues [148] found that advice given by health care providers was often technical, with little advice on how to live with an ICD. Sears and colleagues [149] also found that health care providers are often less comfortable dealing with the emotional aspects of ICDs compared with medical issues.
Once the patient is home, strategies are often implemented by partners to make the transition from hospital to home as smooth as possible. Actions employed include arranging and adapting furniture to allow easier use, words of encouragement to help overcome anger and frustration, and increased activity levels and using games to improve memory deficits and help with reorientating the survivor to their environment. Investigators in this field agree that more could be done to prepare and support families in the longer term after hospital discharge. The burden of caring for a survivor can also have a more severe emotional impact. Pußwald and colleagues [122] found that 6 of 12 family members interviewed were clinically depressed, stating concerns over loss of employment in order to be the main carer and financial worries as being important.

Although the above qualitative studies raise important issues, the small size of the samples means that the themes described above may not encompass all the concerns of post-arrest patients. Furthermore, the literature has concentrated on patients post-arrest with ICDs and may not accurately reflect the general post-arrest population.

\section{Conclusion}

Longer-term survival following OOHCA is improving. Postresuscitation management has been highlighted in the European Resuscitation Council guidelines of 2005. The new 'Chain of Survival' for surviving cardiac arrest now places more emphasis on the final link: 'post-resuscitation care to restore quality of life' [150].

Revascularisation, ICDs, and therapeutic hypothermia appear to have had a considerable impact. Revascularisation and ICDs reduce mortality in the long term mainly by arrhythmia management. However, the considerable financial impact of these interventions means that patient selection is all important to ensure cost-effectiveness. The presence of reversible ischaemia with or without inducible arrhythmia needs to be identified early on in the post-resuscitation management phase. There is a strong argument to be made for early angiography in all post-arrest survivors and electrophysiological testing for those patients without reversible ischaemia. Based on the evidence available, angioplasty appears to have a role to play in revascularisation and its role will become more defined with further research into this area.

Therapeutic hypothermia improves short-term survival and gross neurological outcome. However, its impact on longerterm sequelae has yet to be reported. Although there are inconsistencies in the methodologies used in the various studies, the uniformly positive outcomes mean it should be considered for all cardiac arrest survivors irrespective of the causative arrhythmia. It is likely that outcomes will improve as cooling techniques become more sophisticated, allowing for more rapid and controlled cooling and rewarming. 
Tight glucose control to date is unproven in OOHCA survivors. However, the evidence available suggests that it may be associated with an improved neurological outcome. Given the recommendations for glycaemic control in the critically ill population, it would seem sensible to apply these to post-cardiac arrest patients until further evidence is available. The potential risk for hypoglycaemia and exacerbating cerebral injury needs to be taken into account.

Although mortality is a useful clinical tool for assessing changes in practice, it does not reveal any information about more subtle outcomes important to the patient and their families. Functional dependency and neuropsychiatric sequelae are common and may be due to the initial insult or a response to the critical illness state. A better understanding of the patients' needs after hospital discharge may lead to an improvement in the level of after-care currently provided. This can be achieved only by ensuring that the research agenda include longer-term outcome reporting and that such reporting be sufficiently sophisticated to encompass a multidimensional assessment of quality of survival, impact on families, and future health care needs and costs. In simple terms, producing cohorts of severely damaged survivors is unlikely to be universally regarded as a success.

\section{Competing interests}

The authors declare that they have no competing interests.

\section{Acknowledgement}

SJB is grateful for support from the NIHR Biomedical Research Centre Funding Scheme.

\section{References}

1. Utstein guidelines, European Resuscitation Council [http://www.erc.edu/index.php/doclibrary/en/14/1/].

2. Kalbag A, Kotyra Z, Richards M, Spearpoint K, Brett SJ: Longterm survival and residual hazard after in-hospital cardiac arrest. Resuscitation 2006, 68:79-83.

3. Laver S, Farrow C, Turner D, Nolan J: Mode of death after admission to an intensive care unit following cardiac arrest. Intensive Care Med 2004, 30:2126-2128.

4. Cobbe SM, Dalziel K, Ford I, Marsden AK: Survival of $\mathbf{1 4 7 6}$ patients initially resuscitated from out of hospital cardiac arrest. BMJ 1996, 312:1633-1637.

5. Pell JP, Corstorphine M, McConnachie A, Walker NL, Caldwell JC, Marsden AK, Grubb NR, Cobbe SM: Post-discharge survival following pre-hospital cardiopulmonary arrest due to cardiac aetiology: temporal trends and impact of changes in clinical management. Eur Heart J 2006, 27:406-412.

6. Eisenberg M, Bergner L, Hallstrom A: Survivors of-out-of hospital cardiac arrest: morbidity and long-term survival. $\mathrm{Am} J$ Emerg Med 1984, 2:189-192.

7. Bunch TJ, White RD, Gersh BJ, Meverden RA, Hodge DO, Ballman KV, Hammill SC, Shen WK, Packer DL: Long term outcomes of out-of-hospital cardiac arrest after successful early defibrillation. N Engl J Med 2003, 348:2626-2633.

8. American Heart Association [http://www.americanheart.org].

9. 2005 International Consensus on CPR and ECC Science with Treatment Recommendations [http://www.c2005.org].

10. Cobb LA, Baum RS, Alvarez H 3rd, Schaffer WA: Resuscitation from out-of-hospital ventricular fibrillation: 4 years follow-up. Circulation 1975, 52:223-235.

11. Hallstrom AP, Cobb LA, Yu BH, Weaver WD, Fahrenbruch CE: An antiarrhythmic drug experience in 941 patients resuscitated from an initial cardiac arrest between 1970 and 1985. Am J Cardiol 1991, 68:1025-1031.
12. Goldstein S, Landis JR, Leighton RF, Ritter G, Vasu CM, Wolfe RA, Acheson A, VanderBrug Medendorp S: Predictive survival models for resuscitated victims of out-of-hospital cardiac arrest with coronary heart disease. Circulation 1985, 71:873-880.

13. Rea TD, Crouthamel M, Eisenberg MS, Becker LJ, Lima AR: Temporal patterns in long-term survival after resuscitation from out-of-hospital cardiac arrest. Circulation 2003, 108:11961201.

14. Engdahl J, Bang A, Lindqvist J, Herlitz J: Time trends in longterm mortality after out-of-hospital cardiac arrest, 1980 to 1998, and predictors for death. Am Heart J 2003, 145:826-833.

15. Nolan J: European Resuscitation Council Guidelines for Resuscitation 2005. Resuscitation 2005, 67:S3-S6.

16. Wilber DJ, Garan H, Finkelstein D, Kelly E, Newell J, McGovern B, Ruskin JN: Out-of-hospital cardiac arrest. Use of electro physiologic testing in the prediction of long-term outcome. $N$ Engl J Med 1988, 318:19-24.

17. Nagahara D, Hase M, Tsuchihashi K, Kokubu N, Sakurai S, Yoshioka T, Nishizato K, Fujii N, Uno K, Miura T, et al.: Long term outcome of implanted cardioverter defibrillators in survivors of out-of-hospital cardiac arrest of cardiac origin. Circ J 2006, 70:1128-1132.

18. Bendz B, Eritsland J, Nakstad AR, Brekke M, Klow NE, Steen PA, Mangshau A: Long-term prognosis after out-of-hospital cardiac arrest and primary percutaneous coronary intervention. Resuscitation 2004, 63:49-53.

19. Weaver WD, Cobb LA, Hallstrom AP, Fahrenbruch C, Copass MK, Ray R: Factors influencing survival after out-of hospital cardiac arrest. J Am Coll Cardiol 1986, 7:752-757.

20. Furukawa T, Rozanski JJ, Nogami A, Moroe K, Gosselin AJ, Lister JW: Time-dependent risk of and predictors for cardiac arrest recurrence in survivors of out-of-hospital cardiac arrest with chronic coronary artery disease. Circulation 1989, 80:599-608.

21. Bunch TJ, White RD, Gersh BJ, Shen WK, Hammill SC, Packer DL: Outcomes and in-hospital treatment of out-of-hospital cardiac arrest patients resuscitated from ventricular fibrillation by early defibrillation. Mayo Clin Proc 2004, 79:613-619.

22. Spaulding CM, Joly LM, Rosenberg A, Monchi M, Weber SN, Dhainaut JF, Carli P: Immediate coronary angiography in survivors of out-of-hospital cardiac arrest. N Engl J Med 1997, 336:1629-1633.

23. Kaiser GA, Ghahramani A, Bolooki H, Vargas A, Thurer RJ, Williams WH, Myerburg RJ: Role of coronary artery surgery in patients surviving unexpected cardiac arrest. Surgery 1975, 78:749-754.

24. Every NR, Fahrenbruch CE, Hallstrom AP, Weaver WD, Cobb LA: Influence of coronary bypass surgery on subsequent outcome of patients resuscitated from out of hospital cardiac arrest. J Am Coll Cardiol 1992, 19:1435-1439.

25. Cook JR, Rizo-Patron C, Curtis AB, Gillis AM, Bigger JT Jr., Kutalek SP, Coromilas J, Hofer BI, Powell J, Hallstrom AP, AVD Investigators: Effect of surgical revascularization in patients with coronary artery disease and ventricular tachycardia or fibrillation in the Antiarrhythmics Versus Implantable Defibrillators (AVID) Registry. Am Heart J 2002, 143:821-826.

26. Kelly P, Ruskin JN, Vlahakes GJ, Buckley MJ Jr., Freeman CS, Garan $\mathrm{H}$ : Surgical coronary revascularization in survivors of prehospital cardiac arrest: its effect on inducible ventricular arrhythmias and long-term survival. J Am Coll Cardiol 1990, 15:267-273.

27. Borger van der Burg AE, Bax JJ, Boersma $E$, Bootsma $M$, van Erven L, van der Wall EE, Schalij MJ: Impact of percutaneous coronary intervention or coronary artery bypass grafting on outcome after nonfatal cardiac arrest outside the hospital. $A m$ J Cardiol 2003, 91:785-789.

28. Bigger JT Jr.: Prophylactic use of implanted cardiac defibrillators in patients at high risk for ventricular arrhythmias after coronary-artery bypass graft surgery. Coronary Artery Bypass Graft (CABG) Patch Trial Investigators. N Engl J Med 1997, 337:1569-1575.

29. Marcus FI, Cobb LA, Edwards JE, Kuller L, Moss AJ, Bigger JT Jr., Fleiss JL, Rolnitzky L, Serokman R: Mechanism of death and prevalence of myocardial ischemic symptoms in the terminal event after acute myocardial infarction. Am J Cardiol 1988, 61: 8-15.

30. Uretsky BF, Thygesen K, Armstrong PW, Cleland JG, Horowitz JD, Massie BM, Packer M, Poole-Wilson PA, Ryden L: Acute 
coronary findings at autopsy in heart failure patients with sudden death: results from the assessment of treatment with lisinopril and survival (ATLAS) trial. Circulation 2000, 102:611616.

31. Daoud EG, Niebauer M, Kou WH, Man KC, Horwood L, Morady F, Strickberger SA: Incidence of implantable defibrillator discharges after coronary revascularization in survivors of ischemic sudden cardiac death. Am Heart $J$ 1995, 130:277280.

32. Gregoratos G, Abrams J, Epstein AE, Freedman RA, Hayes DL, Hlatky MA, Kerber RE, Naccarelli GV, Schoenfeld MH, Silka MJ, et al., Committee members and task force members: ACC/AHA/ NASPE 2002 Guideline Update for Implantation of Cardiac Pacemakers and Antiarrhythmia Devices: Summary Article: A Report of the American College of Cardiology/American Heart Association Task Force on Practice Guidelines (ACC/ AHA/NASPE Committee to Update the 1998 Pacemaker Guidelines). Circulation 2002, 106:2145-2161.

33. Heger JJ, Prystowsky EN, Jackman WM, Naccarelli GV, Warfel $\mathrm{KA}$, Rinkenberger RL, Zipes DP: Clinical efficacy and electrophysiology during long-term therapy for recurrent ventricular tachycardia or ventricular fibrillation. N Engl J Med 1981, 305: 539-545.

34. Hallstrom AP, Cobb LA, Yu BH, Weaver WD, Fahrenbruch CE: An antiarrhythmic drug experience in 941 patients resuscitated from an initial cardiac arrest between 1970 and 1985. Am J Cardiol 1991, 68:1025-1031.

35. Haverkamp W, Eckardt L, Borggrefe M, Breithardt G: Drugs versus devices in controlling ventricular tachycardia, ventricular fibrillation, and recurrent cardiac arrest. Am J Cardiol 1997, 80:67G-73G.

36. Moosvi AR, Goldstein S, VanderBrug Medendorp S, Landis JR, Wolfe RA, Leighton R, Ritter G, Vasu CM, Acheson A: Effect of empiric antiarrhythmic therapy in resuscitated out-of-hospital cardiac arrest victims with coronary artery disease. Am J Cardiol 1990, 65:1192-1197.

37. Myerburg R J, Briese FW, Conde C, Mallon SM, Liberthson RR, Castellanos A Jr.: Long-term antiarrhythmic therapy in survivors of prehospital cardiac arrest. Initial 18 months' experience. JAMA 1977, 238:2621-2624.

38. Randomized antiarrhythmic drug therapy in survivors of cardiac arrest (the CASCADE Study). The CASCADE Investigators. Am J Cardiol 1993, 72:280-287.

39. Lee KL, Hafley G, Fisher JD, Gold MR, Prystowsky EN, Talajic M, Josephson ME, Packer DL, Buxton AE; Multicenter Unsustained Tachycardia Trial Investigators: Effect of implantable defibrillators on arrhythmic events and mortality in the multicenter unsustained tachycardia trial. Circulation 2002, 106:233-238.

40. Buxton $A E$, Lee KL, Fisher JD, Josephson ME, Prystowsky EN, Hafley G: A randomised study of the prevention of sudden death in patients with coronary artery disease. $N$ Engl J Med 1999, 341:1882-1890.

41. Moss AJ, Hall WJ, Cannom DS, Daubert JP, Higgins SL, Klein $\mathrm{H}$, Levine JH, Saksena S, Waldo AL, Wiber D, et al.: Improved survival with an implanted defibrillator in patients with coronary disease at high risk for ventricular arrhythmia. Multicenter Automatic Defibrillator Implantation Trial Investigators. N Engl J Med 1996, 335:1933-1940.

42. Greenberg H, Case RB, Moss AJ, Brown MW, Carroll ER, Andrews ML; MADIT-II Investigators: Analysis of mortality events in the Multicenter Automatic Defibrillator Implantation Trial (MADIT-II). J Am Coll Cardiol 2004, 43:1459-1465.

43. A comparison of antiarrhythmic drug therapy with implantable defibrillators in patients resuscitated from near-fatal ventricular arrhythmias. The Antiarrhythmics versus Implantable Defibrillators (AVID) Investigators. N Engl J Med 1997, 337: 1576-1583.

44. Connolly SJ, Gent M, Roberts RS, Dorian P, Roy D, Sheldon RS, Mitchell LB, Green MS, Klein GJ, O'Brien B: Canadian Implantable Defibrillator Study (CIDS): a randomized trial of the implantable defibrillator against amiodarone. Circulation 2000, 101:1297-1302.

45. Kuck KH, Cappato R, Siebels J, Ruppel R: Randomized comparison of antiarrhythmic drug therapy with implantable defibrillators in patients resuscitated from cardiac arrest. The Cardiac Arrest Study Hamburg (CASH). Circulation 2000, 102: 748-754.
46. Connolly SJ, Hallstrom AP, Cappato R, Schron EB, Kuck KH, Zipes DP, Greene HL, Boczor S, Domanski M, Follmann D, et al.: Meta-analysis of the implantable cardioverter defibrillator secondary prevention trials. AVID, CASH, CIDS studies. Antiarrhythmics vs. Implantable Defibrillator Study. Cardiac Arrest Study Hamburg. Canadian Implantable Defibrillator Study. Eur Heart J 2000, 21:2071-2078.

47. Bokhari F, Newman D, Greene M, Korley V, Mangat I, Dorian P: Long-term comparison of the implantable cardioverter defibrillator versus amiodarone: eleven-year follow-up of a subset of patients in the Canadian Implantable Defibrillator Study (CIDS). Circulation 2004, 110:112-116.

48. Hennersdorf MG, Niebch V, Vester EG, Winter J, Perings C, Strauer BE: Long-term follow-up of sudden cardiac arrest survivors and electrophysiologically guided antiarrhythmic therapy. Cardiology 2003, 99:190-197.

49. Wever E F, Hauer RN, van Capelle FL, Tijssen JG, Crijns HJ, Algra A, Wiesfeld AC, Bakker PF, Robles de Medina EO: Randomized study of implantable defibrillator as first-choice therapy versus conventional strategy in post infarct sudden death survivors. Circulation 1995, 91:2195-2003.

50. Powell AC, Fuchs $T$, Finkelstein DM, Garan H, Cannom DS McGovern BA, Kelly E, Vlahakes GJ, Torchiana DF, Ruskin JN: Influence of implantable cardioverter-defibrillators on the long-term prognosis of survivors of out-of-hospital cardiac arrest. Circulation 1993, 88:1083-1092.

51. Crandall BG, Morris CD, Cutler JE, Kudenchuk PJ, Peterson JL, Liem LB, Broudy DR, Greene HL, Halperin BD, McAnulty JH: Implantable cardioverter-defibrillator therapy in survivors of out-of-hospital sudden cardiac death without inducible arrhythmias. J Am Coll Cardiol 1993, 21:1186-1192.

52. Connolly SJ, Dorian P, Roberts RS, Gent M, Bailin S, Fain ES, Thorpe K, Champagne J, Talajic M, Coutu B, Gronefeld GC, Hohnloser SH; for the Optimal Pharmacological Therapy in Cardioverter Defibrillator Patients (OPTIC) Investigators: Comparison of B-blocker, amiodarone plus B-blocker, or sotalol for prevention of shocks from implantable cardioverter defibrillators: the OPTIC Study: a randomized trial. JAMA 2006, 295: 165-171.

53. Negovsky VA: Postresuscitation disease. Crit Care Med 1988, 16:942-946

54. Cummins RO, Chamberlain DA, Abramson NS, Allen M, Baskett PJ, Becker L, Bossaert L, Delooz HH, Dick WF, Eisenberg MS, et al.: Recommendation guidelines for uniform reporting of data from out-of-hospital cardiac arrest: the Utstein style. A statement for health professionals from a task force of the American Heart Association, the European Resuscitation Council, the Heart and Stroke Foundation of Canada, and the Australian resuscitation Council. Circulation 1991, 84:960-975.

55. Kern KB, Hilwig RW, Rhee KH, Berg RA: Myocardial dysfunction after resuscitation from cardiac arrest: an example of global myocardial stunning. J Am Coll Cardiol 1996, 28:232240.

56. Laurent I, Monchi M, Chiche JD, Joly LM, Spaulding C, Bourgeois B, Cariou A, Rozenberg A, Carli P, Weber S, et al.: Reversible myocardial dysfunction in survivors of out-of-hospital cardiac arrest. J Am Coll Cardio/ 2002, 40:2110-2116.

57. Mullner M, Domanovits H, Sterz F, Herkner H, Gamper G, Kurkciyan I, Laggner AN: Measurement of myocardial contractility following successful resuscitation: quantitated left ventricular systolic function utilising non-invasive wall stress analysis. Resuscitation 1998, 39:51-59.

58. Palmer BS, Hadziahmetovic M, Veci T, Angelos MG: Global ischemic duration and reperfusion function in the isolated perfused rat heart. Resuscitation 2004, 62:97-106.

59. Xie J, Weil MH, Sun S, Tang W, Sato $Y$, Jin X, Bisera J: Highenergy defibrillation increases the severity of postresuscitation myocardial dysfunction. Circulation 1997, 96:683-688.

60. Gazmuri RJ, Deshmukh S, Shah PR: Myocardial effects of repeated electrical defibrillation in the isolated fibrillating rat heart. Crit Care Med 2000, 28:2690-2696.

61. Tang W, Weil MH, Sun S, Yamaguchi H, Povoas HP, Pernat AM, Bisera J: The effects of biphasic and conventional monophasic defibrillation on postresuscitation myocardial function. $J \mathrm{Am}$ Coll Cardiol 1999, 34:815-822.

62. Tang W, Weil MH, Sun S, Jorgenson D, Morgan C, Klouche K, Synder D: The effects of biphasic waveform design on post- 
resuscitation myocardial function. J Am Coll Cardiol 2004, 43: 1228-1235.

63. Tang W, Weil MH, Sun S, Noc M, Yang L, Gazmuri RJ: Epinephrine increases the severity of postresuscitation myocardial dysfunction. Circulation 1995, 92:3089-3093.

64. Chang WT, Ma MH, Chien KL, Huang CH, Tsai MS, Shih FY, Yuan A, Tsai KC, Lin FY, Lee YT, et al:: Postresuscitation myocardial dysfunction: correlated factors and prognostic implications. Intensive Care Med 2007, 33:88-95.

65. Kern KB, Hilwig RW, Berg RA, Rhee KH, Sanders AB, Otto CW, Ewy GA: Postresuscitation left ventricular systolic and diastolic dysfunction: treatment with dobutamine. Circulation 1997, 95:2610-2613.

66. Huang L, Weil MH, Sun S, Cammarata G, Cao L, Tang W: Levosimendan improves postresuscitation outcomes in a rat model of CPR. J Lab Clin Med 2005, 146:256-261.

67. Tennyson H, Kern KB, Hilwig RW, Berg RA, Ewy GA: Treatment of postresuscitation myocardial dysfunction: aortic counterpulsation versus dobutamine. Resuscitation 2002, 54:69-75

68. Vasquez A, Kern KB, Hilwig RW, Heidenreich J, Berg RA, Ewy GA: Optimal dosing of dobutamine for treating post-resuscitation left ventricular dysfunction. Resuscitation 2004, 61:199207.

69. Bernard SA, Gray TW, Buist MD, Jones BM, Silvester W, Gutteridge G, Smith K: Treatment of comatose survivors of out-ofhospital cardiac arrest with induced hypothermia. $N$ Engl J Med 2002, 346:557-563.

70. White BC, Grossman LI, O'Neil BJ, DeGracia DJ, Neumar RW, Rafols JA, Krause GS: Global brain ischemia and reperfusion. Ann Emerg Med 1996, 27:588-594.

71. Nagao K, Hayashi N, Kanmatsuse K, Arima K, Ohtsuki J, Kikushima K, Watanabe I: Cardiopulmonary cerebral resuscitation using emergency cardiopulmonary bypass, coronary reperfusion therapy and mild hypothermia in patients with cardiac arrest outside the hospital. J Am Coll Cardiol 2000, 36: 776-783

72. Illievich UM, Zornow MH, Choi KT, Scheller MS, Strnat MA: Effects of hypothermia metabolic suppression on hippocampal glutamate concentrations after transient global cerebral ischemia. Anesth Analg 1994, 78:905-911.

73. Oku K, Kuboyama K, Safar P, Obrist W, Sterz F, Leonov $Y$, Tisherman SA: Cerebral and systemic arteriovenous oxygen monitoring after cardiac arrest. Inadequate cerebral oxygen delivery. Resuscitation 1994, 27:141-152.

74. Sterz F, Safar P, Tisherman S, Radovsky A, Kuboyama K, Oku K: Mild hypothermic cardiopulmonary resuscitation improves outcome after prolonged cardiac arrest in dogs. Crit Care Med 1991, 19:379-389.

75. Safar $P$ : Resuscitation from clinical death: pathophysiologic limits and therapeutic potentials. Crit Care Med 1988, 16:923-941.

76. Kuboyama K, Safar P, Radovsky A, Tisherman SA, Stezoski SW, Alexander $\mathrm{H}$ : Delay in cooling negates the beneficial effect of mild resuscitative cerebral hypothermia after cardiac arrest in dogs: a prospective, randomized study. Crit Care Med 1993, 21:1348-1358

77. Yanagawa $\mathrm{Y}$, Ishihara $\mathrm{S}$, Norio $\mathrm{H}$, Takino M, Kawakami M, Takasu A, Okamoto K, Kaneko N, Terai C, Okada Y: Preliminary clinical outcome study of mild resuscitative hypothermia after out-ofhospital cardiopulmonary arrest. Resuscitation 1998, 39:61-66.

78. Bernard SA, Jones BM, Horne MK: Clinical trial of induced hypothermia in comatose survivors of out-of-hospital cardiac arrest. Ann Emerg Med 1997, 30:146-153.

79. Hypothermia after Cardiac Arrest Study Group: Mild therapeutic hypothermia to improve the neurologic outcome after cardiac arrest. N Engl J Med 2002, 346:549-556.

80. Oddo M, Schaller MD, Feihl F, Ribordy V, Liaudet L: From evidence to clinical practice: effective implementation of therapeutic hypothermia to improve patient outcome after cardiac arrest. Crit Care Med 2006, 34:1865-1873.

81. Holzer M, Bernard SA, Hachimi-Idrissi S, Roine RO, Sterz F, Mullner $\mathrm{M}$; on behalf of the Collaborative Group on Induced Hypothermia for Neuroprotection After Cardiac Arrest: Hypothermia for neuroprotection after cardiac arrest: systemic review and individual patient data meta-analysis. Crit Care Med 2005, 33:414-418.

82. Zeiner A, Holzer $M$, Sterz $F$, Behringer $W$, Schorkhuber $W$, Mullner M, Frass M, Siostrzonek P, Ratheiser K, Kaff A, et al.: Mild resuscitative hypothermia to improve neurological outcome after cardiac arrest: a clinical feasibility trial. Hypothermia After Cardiac Arrest (HACA) Study Group. Stroke 2000, 31:8694.

83. Nolan JP, Morley PT, Vanden Hoek TL, Hickey RW, Kloeck WG, Billi J, Bottiger BW, Morley PT, Nolan JP, Okada K, et al.; International Liaison Committee on Resuscitation: Therapeutic hypothermia after cardiac arrest: an advisory statement by the advanced life support task force of the International Liaison Committee on Resuscitation. Circulation 2003, 108:118-122.

84. Wolfrum S, Radke PW, Pischon T, Willich SN, Schunkert H, Kurowski V: Mild therapeutic hypothermia after cardiac arrest-a nationwide survey on the implementation of the ILCOR guidelines in German intensive care units. Resuscitation 2007, 72:207-213.

85. Abella BS, Rhee JW, Huang KN, Vanden Hoek TL, Becker LB: Induced hypothermia is underused after resuscitation from cardiac arrest: a current practice survey. Resuscitation 2005, 64:181-186.

86. Merchant RM, Soar J, Skrifvars MB, Silfvast T, Edelson DP, Ahmad F, Huang KN, Khan M, Vanden Hoek TL, Becker LB, et al:: Therapeutic hypothermia utilization among physicians after resuscitation from cardiac arrest. Crit Care Med 2006, 34: 1935-1940.

87. Laver SR, Padkin A, Atalla A, Nolan JP: Therapeutic hypothermia after cardiac arrest: a survey of practice in intensive care units in the United Kingdom. Anaesthesia 2006, 61:873-877.

88. van den Berghe $G$, Wouters $P$, Weekers $F$, Verwaest $C$, Bruyninckx F, Schetz ZM, Vlasselaers D, Ferdinande P, Lauwers $P$, Bouillon R: Intensive insulin therapy in the critically ill patients. N Engl J Med 2001, 345:1359-1367.

89. Dellinger RP, Carlet JM, Masur $\mathrm{H}$, Gerlach $\mathrm{H}$, Calandra $\mathrm{T}$, Cohen J, Gea-Banacloche J, Keh D, Marshall JC, Parker MM, et al.: Surviving Sepsis Campaign guidelines for management of severe sepsis and septic shock. Intensive Care Med 2004, 30: 536-555.

90. Van den Berghe G, Wilmer A, Hermans G, Meersseman W, Wouters PJ, Milants I, Van Wijingaerden E, Bobbaers $\mathrm{H}$, Bouillon R: Intensive insulin therapy in the medical ICU. N Engl J Med 2006, 354:449-461

91. Frontera JA, Fernandez A, Claassen J, Schmidt M, Schumacher HC, Wartenberg K, Temes R, Parra A, Ostapkovich ND, Mayar SA: Hyperglycaemia after SAH: predictors, associated complications and impact on outcome. Stroke 2006, 37:199-203.

92. Dorhout Mees SM, van Dijk GW, Algra A, Kempink DR, Rinkel GJ: Glucose levels and outcome after subarachnoid hemorrhage. Neurology 2003, 61:1132-1133.

93. Gray CS, Hildreth AJ, Sandercock PA, O'Connell JE, Johnston DE, Cartlidge NE, Bamford JM, James OF, Alberti KG; GIST Trialists Collaboration: Glucose-potassium-insulin infusions in the management of post-stroke hyperglycaemia: the UK Glucose Insulin Stroke Trial. Lancet Neurol 2007, 6:397-406.

94. Steingrub JS, Mundt DJ: Blood glucose and neurologic outcome with global brain ischaemia. Crit Care Med 1996, 24: 802-806.

95. Longstreth WT, Diehr P, Cobb LA, Hanson RW, Blair AD: Neurologic outcome and blood glucose levels during out-of-hospital cardiopulmonary resuscitation. Neurology 1986, 36: 1186-1191.

96. Mullner M, Sterz F, Binder M, Schreiber W, Deimel A, Laggner AN: Blood glucose concentration after cardiopulmonary resuscitation influences functional neurological recovery in human cardiac arrest survivors. J Cereb Blood Flow Metab 1997, 17:430-436.

97. Langhelle A, Tyvold SS, Lexow K, Hapnes SA, Sunde K, Steen PA: In-hospital factors associated with improved outcome after out-of-hospital cardiac arrest. A comparison between four regions in Norway. Resuscitation 2003, 56:247-263.

98. Skrifvars MB, Pettila V, Rosenberg PH, Castren M: A multiple logistic regression analysis of in-hospital factors related to survival at six months in patients resuscitated from out-ofhospital ventricular fibrillation. Resuscitation 2003, 59:319328.

99. Snyder BD, Hauser WA, Loewenson RB, Leppik IE, RamirezLassepas M, Gumnit RJ: Neurologic prognosis after cardiopulmonary arrest: III. Seizure activity. Neurology 1980, 30: $1292-1297$ 
100. Krumholz A, Stern BJ, Weiss HD: Outcome from coma after cardiopulmonary resuscitation: relation to seizures and myoclonus. Neurology 1988, 38:401-405.

101. Chan SA, Reid KH, Schurr A, Miller JJ, Iver V, Tseng MT: Fosphenytoin reduces hippocampal neuronal damage in rat following transient global ischemia. Acta Neurochir (Wien) 1998, 140:175-180.

102. Crumrine, RC, Bergstrand K, Cooper AT, Faison WL, Cooper BR: Lamotrogine protects hippocampal CA1 neurons from ischemic damage after cardiac arrest. Stroke 1997, 28:22302236.

103. Lin SR, O'Connor MJ, Fischer HW, King A: The effect of combined dextran and streptokinase on cerebral function and blood flow after cardiac arrest: an experimental study on the dog. Invest Radiol 1978, 13:490-498.

104. Fischer M, Böttiger BW, Popov-Cenic S, Hossmann KA: Thrombolysis using plasminogen activator and heparin reduces cerebral no-reflow after resuscitation from cardiac arrest: an experimental study in the cat. Intensive Care Med 1996, 22: 1214-1223.

105. Nishizawa H, Kudoh I: Cerebral autoregulation is impaired in patients resuscitated after cardiac arrest. Acta Anaesthesiol Scand 1996, 40:1149-1153.

106. Sundgreen C, Larsen FS, Herzog TM, Knudsen GM, Boesgaard $\mathrm{S}$, Aldershvile J: Autoregulation of cerebral blood flow in patients resuscitated from cardiac arrest. Stroke 2001, 32: 128-132.

107. Jennett $B$, Bond $M$ : Assessment of outcome after severe brain damage. Lancet 1975, 1:480-484.

108. A randomized clinical trial of cardiopulmonary-cerebral resuscitation: design, methods, and patient characteristics. Brain Resuscitation Clinical Trial I Study Group. Am J Emerg Med 1986, 4:72-86

109. Cummins RO, Chamberlain D, Hazinski MF, Nadkarni V, Kloeck W, Kramer E, Becker L, Robertson C, Koster R, Zaritsky A, et al.: Recommended guidelines for reviewing, reporting, and conducting research on in hospital resuscitation: the in-hospital 'Utstein style'. A statement for healthcare professionals from the American Heart Association, the European Resuscitation Council, the Heart and Stroke Foundation of Canada, the Australian Resuscitation Council, and the Resuscitation Councils of Southern Africa. Resuscitation 1997, 34:151-183.

110. Lundgren-Nilsson A, Rosen H, Hofgren C, Sunnerhagen KS: The first year after successful cardiac resuscitation: function, activity, participation and quality of life. Resuscitation 2005 , 66:285-289.

111. Graves JR, Herlitz J, Bang A, Axelsson A, Ekstrom L, Holmberg M, Lindqvist J, Sunnerhagen K, Holmberg S: Survivors of out of hospital cardiac arrest: their prognosis, longevity and functional status. Resuscitation 1997, 35:117-121.

112. Hsu JW, Madsen CD, Callaham ML: Quality-of-life and formal functional testing of survivors of out-of-hospital cardiac arrest correlates poorly with traditional neurologic outcome scales. Ann Emerg Med 1996, 28:597-605.

113. Langhelle A, Nolan J, Herlitz J, Castren M, Wenzel V, Soreide E, Ehgdahl J, Steen PA; 2003 Utstein Consenses Symposium: Recommended guidelines for reviewing, reporting, and conducting research on post-resuscitation care: the Utstein style. Resuscitation 2005, 66:271-283.

114. EuroQol-a new facility for the measurement of health-related quality of life. The EuroQol Group. Health Policy 1990, 16:199208.

115. Hays RD, Sherbourne CD, Mazel RM: The RAND 36-Item Health Survey 1.0. Health Econ 1993, 2:217-227.

116. Sintonen $\mathrm{H}$ : The 15D instrument of health-related quality of life: properties and applications. Ann Med 2001, 33:328-336.

117. Katz S, Ford AB, Moskowitz RW, Jackson BA, Jaffe MW: Studies of illness in the aged. The index of ADL: a standardised measure of biological and psychosocial function. JAMA 1963, 185:914-919.

118. Asberg K, Sonn U: The cumulative structure of personal and instrumental ADL. A study of elderly people in a health service district. Scand J Rehabil Med 1989, 21:171-177.

119. Rosen H, Sunnerhagen KS, Herlitz J, Blomstrand C, Rosengren L: Serum levels of the brain-derived proteins S-100 and NSE predict long-term outcome after cardiac arrest. Resuscitation 2001, 49:183-191.
120. Sunnerhagen K, Johansson O, Herlitz J, Grimby G: Life after cardiac arrest: a retrospective study. Resuscitation 1996, 31: 135-140.

121. Grosvasser S, Cohen M, Costeff H: Rehabilitation outcome after anoxic brain damage. Arch Phys Med Rehabil 1989, 70: 186-188.

122. Pußwald S, Fertl E, Faltl M, Auff E: Neurological rehabilitation of severely disabled cardiac arrest survivors. Part II. Life situation of patients and families after treatment. Resuscitation 2000, 47:241-248.

123. Sauve MJ: Long-term physical functioning and psychosocial adjustment in survivors of sudden cardiac death. Heart Lung 1995, 24:133-144.

124. Dobson M, Tattersfield AE, Adler MW, McNicole MW: Attitudes and long-term adjustment of patients surviving cardiac arrest. BMJ 1971, 3:207-212.

125. Kalbfleisch KR, Lehmann MH, Steinman RT, Jackson K, Axtell K, Schuger CD, Tchou PJ: Reemployment following implantation of the automatic cardioverter defibrillator. Am J Cardiol 1989, 64:199-202.

126. Granja C, Teixeira-Pinto A, Costa-Pereira A: Quality of life after intensive care - evaluation with EQ-5D questionnaire. Intensive Care Med 2002, 7:898-907.

127. Kuilman M, Bleeker JK, Hartman JA, Simoons ML: Long-term survival after out-of-hospital cardiac arrest: an 8-year follow-up. Resuscitation 1999, 41:25-31.

128. Sauve MJ, Walker JA, Massa SM, Winkle RA, Scheinman MM: Patterns of cognitive recovery in sudden cardiac arrest survivors: the pilot study. Heart Lung 1996, 25:172-181.

129. Bunch TJ, White RD, Smith GE, Hodge DO, Gersh BJ, Hammill SC, Shen WK, Packer DL: Long-term subjective memory function in ventricular fibrillation out-of-hospital cardiac arrest survivors resuscitated by early defibrillation. Resuscitation 2004, 60:189-195.

130. Roine RO, Kajaste S, Kaste M: Neuropsychological sequelae of cardiac arrest. JAMA 1993, 269:237-242.

131. Ladwig KH, Schoefinius A, Dammann G, Danner R, Gurtler R, Herrmann R: Long-acting psychotraumatic properties of a cardiac arrest experience. Am J Psychiatry 1999, 156:912-919.

132. Bertini G, Giglioli C, Giovannini F, Bartoletti A, Cricelli F, Margheri $M$, Russo L, Taddei T, Taiti A: Neuropsychological outcome of survivors of out-of-hospital cardiac arrest. J Emerg Med 1990, 8:407-412.

133. Grubb NR, O'Carroll R, Cobbe SM, Sirel J, Fox KA: Chronic memory impairment after cardiac arrest outside hospital. $B M J$ 1996, 313:143-146.

134. Beuret $P$, Feihl F, Vogt $P$, Perret A, Romand JA, Perret C: Cardiac arrest: prognostic factors and outcome at one year. Resuscitation 1993, 25:171-179.

135. Dlin B: The experience of surviving almost certain death. Adv Psychosom Med 1980, 10:111-118.

136. Druss RG, Kornfeld DS: The survivors of cardiac arrest: a psychiatric study. JAMA 1967, 201:291-296

137. O'Reilly SM, Grubb N, O'Carroll RE: Long-term emotional consequences on in-hospital cardiac arrest and myocardial infarction. Br J Clin Psychol 2004, 43:83-95.

138. Dougherty CM: Longitudinal recovery following sudden cardiac arrest and internal cardioverter implantation: survivors and their families. Am J Crit Care 1994, 3:145-154.

139. Bedell SE, Delbanco TL, Cook EF, Epstein FH: Survival after cardiopulmonary resuscitation in the hospital. $N$ Engl J Med 1983, 309:569-576

140. American Psychiatric Association: Diagnostic and Statistical Manual of Mental Disorders. 4th edition. Washington, DC: American Psychiatric Association; 1994.

141. Sukantarat K, Greer S, Brett S, Williamson R: Physical and psychological sequelae of critical illness. $\mathrm{Br} J$ Health Psychol 2007, 12:65-74.

142. Jackson JC, Hart RP, Gordon SM, Shintani A, Truman B, May L, Ely EW: Six month neuropsychological outcome of medical intensive care patients. Crit Care Med 2003, 31:1226-1234.

143. Hopkins RO, Weaver LK, Pope D, Orme JF, Bigler ED, LarsonLOHR V: Neuropsychological sequelae and impaired health status in survivors of severe acute respiratory distress syndrome. Am J Respir Crit Care Med 1999, 160:50-56.

144. Rothenhausler HB, Ehrentraut S, Stoll C, Schelling G, Kapfhammer HP: The relationship between cognitive performance and 
employment and health status in long-term survivors of the acute respiratory distress syndrome: results of an exploratory study. Gen Hosp Psychiatry 2001, 23:90-96.

145. Hopkins RO, Weaver LK, Collingridge D, Parkinson RB, Chan KJ, Orme JF Jr.: Two-year cognitive, emotional, and quality-of-life outcomes in acute respiratory distress syndrome. Am J Respir Crit Care Med 2005, 171:340-347.

146. Hopkins RO, Brett S: Chronic neurocognitive effects of critical illness. Curr Opin Crit Care 2005, 11:369-375.

147. Dougherty CM, Pyper GP, Benoliel JQ: Domains of concern of intimate partners of sudden cardiac arrest survivors after ICD implantation. J Cardiovasc Nurs 2004, 19:21-31.

148. Tagney J, James JE, Albarran JW: Exploring the patient's experiences of learning to live with an implantable cardioverter defibrillator (ICD) from one UK centre: a qualitative study. Eur $J$ Cardiovasc Nurs 2003, 2:195-203.

149. Sears SF, Todaro JF, Urizar G, Lewis TS, Sirois B, Wallace $R$ Sotile W, Curtis AB, Conti JB: Assessing the psychosocial impact of the ICD: a national survey of implantable cardioverter defibrillator health care providers. Pacing Clin Electrophysiol 2000, 23:939-945.

150. Nolan J, Soar J, Eikeland H: The chain of survival. Resuscitation 2006, 71:270-271.

151. Scottish Intercollegiate Guidelines Network (SIGN) [http:// www.sign.ac.uk] 